\title{
ANALYSIS OF AUTONOMIC NERVOUS SYSTEM FUNCTIONAL AGE AND HEART RATE VARIABILITY IN MINE WORKERS
}

\author{
Vasicko T, Prindesova-Busikova J, Osina O.
}

Clinic of Occupational Medicine and Toxicology, Comenius University,

Jessenius Faculty of Medicine and University Hospital, Martin, Slovakia

\begin{abstract}
Introduction: Heavy working conditions and many unpropitious factors influencing workers health participate in development of various health disorders, among other autonomic cardiovascular regulation malfunction. The aim of this study is to draw a comparison of autonomic nervous system functional age and heart rate variability changes between workers with and without mining occupational exposure.

Material and methods: Short term HRV was measured by DiANS PF8 device in men with and without occupational mining exposure (exposure for 10 years at least) using standard orthoclinostathic protocol (each phase 300 $\mathrm{sec}$ or 300 heartbeats if heart rate under $60 \mathrm{bpm}$ ), excluding those with severe cardiovascular, metabolic, or psychiatric diseases, nicotine and other drugs abuse, as well as those, who underwent heavy stress situation during last year.

Results: Evaluating $41 \mathrm{HRV}$ records among miners ( $\mathrm{n}=24$, age $47.9 \pm 6.1$ years, exposure $22.5 \pm 5$ years) and non-miners ( $n=17$, age $48.5 \pm 6.9$ years) we found significantly increased difference between functional age of ANS and calendar age in miners group $(+7.2 \pm 7.3$ years) over against the non-miners group ( $-1.6 \pm 6.5$ years). No correlation was found between exposure duration and functional age of ANS difference. Analysis of HRV parameters show significant reduction in total spectral power, LF, HF and rMSSD in mine workers above 48 years of age.

Discussion and conclusion: Our results show that influence of occupational work factors from mining exposure can clearly take part in worsening the reactivity of ANS, which can be associated with greater risk of developing mostly cardiovascular diseases. It is important to think of non-occupational factors improving or deteriorating ANS reactivity and of individual sensitivity to other external factors.
\end{abstract}

Key words: mining, autonomic nervous system, heart rate variability, functional age

\section{INTRODUCTION}

Occupation of a miner, first as craft, afterwards as mining industry, has a very long tradition in Slovakia, reaching to antique epoch, although the first signs of mining activities are known since prehistoric age. In this region, there was and still is mined wide range of different materials.

Workers in mining professions as driller, breaker, mechanician and machine fitter, serviceman, electrician, locomotive driver and others are exposed to the whole spectrum of specific and non-specific risk factors of mine environment. Miner s work is physically demanding and significantly associated with factors that may cause chronic professional stress. Working under the influence of adverse conditions in these workers often may lead to various health damages.

Employees working in mining professions represent the major part of patients hospitalized at the Clinic of Occupational Medicine and Toxicology at University Hospital in Martin, Slovakia. According to data from the Statistical Office of Slovak Republic, in 2014 totally 6939 people were employed in 34 industrial companies aimed at the mining and auxiliary works in the industrial sector of mining and quarrying (1).

The analysis of heart rate variability (HRV) is a non-invasive and sufficiently sensitive method to assess various influences to cardiovascular activity, from central nervous or endocrine system, through respiration and local influences (e.g. physical and mental strain,

Address for correspond e n c e:

Assoc.Prof. Osina O., MD, PhD, Clinic of Occupational Medicine and Toxicology, Jessenius Faculty of Medicine and University Hospital, 03601 Martin, Kollarova str. 2, 03601 Martin, Slovakia, e-mail: osina@jfmed.uniba.sk, Phone +421 434132836 
stress and exogenous factors). Heart rate variability is thus a parameter reflecting the complex regulation of cardiac activity with uppermost impact of the autonomic nervous system (ANS) (2). Evaluation of HRV in spectral domain (spectral or frequency analysis, SA HRV) is generally considered as the appropriate non-invasive method for assessing the activity of ANS. Individual indices of SA HRV often give somewhat inconclusive and antagonistic results. From the beginning up to recent studies they all show similar changes in HRV in connection with increasing age, in which case the most significant changes were seen in the age groups between 35 and 55 years old, after 55th year of life the HRV parameters changing just slowly. From all studied parameters of SA HRV, there was found significant reduction of total HRV with increasing age, significant decrease was noticed also in parasympathetic activity (high frequency band, HF), sympathetic activity, as well as increase of LF/HF ratio, indicating a dysregulation to the side of sympathetic dominance (3). This positive or negative age-dependence of various SA HRV parameters may cause very difficult interpretation of SA HRV among various age groups (4).

The newer method of HRV analysis uses three complex indices, which combine all agedependent parameters gained from the orthoclinostatic test: complex index of vagal activity, complex index of sympatovagal balance and total score of SA HRV, which are called the functional age of ANS (FA ANS). This method enables easier orientation and simpler interpretation of the SA HRV (5).

The aim of this work is to assess the impact of mine work on autonomic nervous system by monitoring the heart rate variability in the subjects with and without occupational mining exposure and complex evaluation of the parameters of HRV frequency domain analysis, including the set of age-dependent complex indices known as functional age of autonomic nervous system.

\section{MATERIAL AND METHODS}

This study was designed as a cross-sectional study with comparing HRV frequency domain analysis parameters in two groups of men (with and without mining exposure) from one-shot measuring of HRV under standardized conditions. All subjects in both groups were selected from patients of Clinic of Occupational Medicine and Toxicology JFM CU and University Hospital in Martin. The subjects assigned to the first (miners) group were men between 36 and 57 years of age with the exposure to one of mining professions for at least 10 years (mining as a current job or less than 5 years after the last mining exposure). The second (control) group consisted of men aged from 36 to 58 years old with no exposure to mining profession ever - we selected only the subjects working in occupation categorized in group 1 or 2 for risk factors (physical load, noise, vibrations and forced postures during work). Relative healthy subjects without severe hypertension or other cardiovascular disease (as well as autonomic imbalance with tendency to collapses), diabetes nor psychiatric diseases or drug and alcohol abuse were included in both groups. The subjects using the medication which may affect the cardiovascular system and central or autonomic nervous system and ones who underwent stressful event during last year were excluded from main and control group. A few rules for intake of specific substances were set out - use of alcohol or caffeine beverages and medication was not allowed 12 hours before examination, as well as smoking at least 4 hours before examining. The subjects were asked to sleep at least 5 or 6 hours a night before examination and to avoid excessive physical activity, stress and emotional strain or irritating food in the day of examination. All subjects confirmed they have been informed about whole examination process from examiner, afterwards they filled in the short entrance questionnaire.

For HRV registration the system DiANS PF8 (Dimea Group, Olomouc, Czech Republic), consisting of a chest electrode band, an amplifier and a laptop was used. All examinations were performed according to a standardized protocol for examining the short-term HRV dur- 
ing morning time (between 7.30 and $11.00 \mathrm{AM}$ ). HRV has been recorded in the first supination (T1 phase), orthostatic (T2 phase) and second supination body position (T3 phase), each lasting 300 seconds or $300 \mathrm{R}-\mathrm{R}$ intervals (if heart rate under $60 \mathrm{bpm}$ ). At the very beginning of examination the subjects stayed in rest in supination position for about 2 to 5 minutes until cardiovascular functions became stable. All body position changes during the examination were followed by 60 second lasting stabilization phase, just then has been provided the proper recording in particular body position.

\section{Statistical analysis}

The data were processed and statistically evaluated using Medical DiANS PC software (frequency domain analysis of raw HRV source, FA ANS analysis), MS Excel 2013 and Salstat2 (statistical analysis). FA ANS and difference between the FA ANS and calendar age of each subject were calculated from the data from T2 and T3 phase (orthostatic and second supination position). From the parameters of SA HRV following parameters were computed: Total Spectral Power (TotPwr), spectral power in HF band (HF, frequency range from 0.15 to $0.40 \mathrm{~Hz}$, which reflects heart rate changes under vagal and respiratory influence (6)), spectral power in LF band (LF, frequency range from 0.04 to $0.15 \mathrm{~Hz}$, related to the baroreflex regulation (7) and vasomotor activity under both sympathetic and parasympathetic influences) and the LF/HF ratio (may indicate higher sympathetic activity relative to parasympathetic activity, but should be interpreted with taking the mean values of HF and LF power into consideration). For comparison, from the time domain analysis HRV the rMSSD parameter (root mean square of successive differences) was calculated (reflects beat-to-beat variance and is used to estimate the vagally-mediated changes and typically provides a better assessment of respiratory sinus arrhythmia than pNN50 - the percentage of adjacent NN intervals that differ from each other by more than $50 \mathrm{~ms}$ - especially in older subjects (8)). The difference between FA ANS and calendar age for both groups of subjects was assessed by using the two-sample t-test for independent samples and Yates chi-square test. The results of SA HRV, due to their physiological changes with age, were divided into two subgroups by the age in both miners and control group - subjects under and over 48 years of age (according to median calendar age in miners group), and those data were statistically evaluated using non-parametric Mann-Whitney U test. The correlation between FA ANS - calendar age difference and mining exposure duration was evaluated as well.

\section{RESULTS}

From all HRV records we selected 41 records overall, 24 records in miners group and 17 records in control group. Average calendar age in miners group was 47.92 years (SD 6.11) and in control group 48.53 years (SD 6.90). Average FA ANS in miners group was 55.10 years (SD 11.7), in control group 46.94 years (SD 10.03). The difference between functional age of ANS and calendar age in miners group was +7.19 years (SD 7.47) and in control group was - 1.59 years (SD 6.71). The comparison of basic data from both groups are given in the Fig. 1 and Table 1. Statistical analysis shows a highly significant elevation of difference between FA ANS and calendar age in the miners group compared with the control group (ttest $\mathrm{t}=3.93, \mathrm{p}=0.0004)$. Evaluation of the quantity in both groups shows increased FA ANS compared to calendar age in 21 subjects out of the total 24 subjects in this group, decreased difference between FA ANS and calendar age was found only in 3 subjects. In control group, increased FA ANS was found in 6 subjects and increased FA ANS in 11 subjects of total amount 17. This result has been evaluated as highly significant as well (chi-square $\mathrm{p}=0.0017$. 


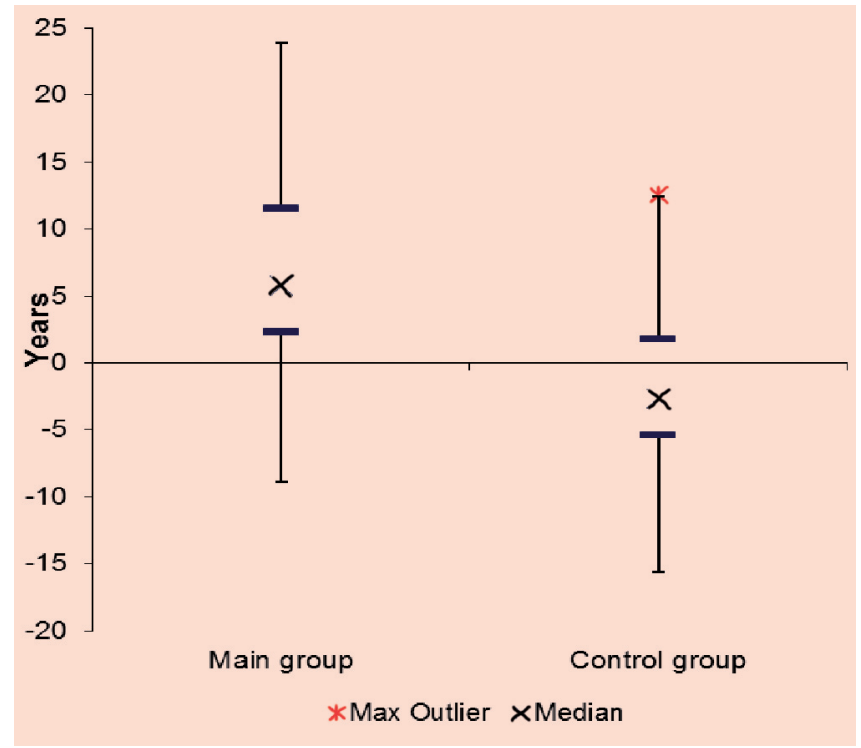

Fig. 1 Difference between functional age of ANS and calendar age in miners and control group. The significant difference was found $(p=0.0004)$.

Table 1. Comparison of basic characteristics from miners and control group, including average calendar age, average functional age and average difference between functional age of ANS and calendar age in both groups. Values are presented as mean value, standard deviation (SD), standard error (SE), and interquartile range (IGR).

\begin{tabular}{|l|c|c|}
\hline & $\begin{array}{c}\text { Miners group } \\
\text { (n = 24) }\end{array}$ & $\begin{array}{c}\text { Control group } \\
\text { (n }=17)\end{array}$ \\
\hline Average calendar age (years) & 47.92 & 48.53 \\
SD & 6.11 & 6.90 \\
SE & 1.25 & 1.67 \\
IQR & 9.25 & 11.67 \\
\hline Average functional age of ANS (years) & 55.10 & 46.94 \\
SD & 11.70 & 10.03 \\
SE & 2.39 & 2.43 \\
IQR & 18.79 & 11.72 \\
\hline FA ANS and calendar age average difference (years) & +7.19 & -1.59 \\
SD & 7.47 & 6.71 \\
SE & 1.53 & 1.63 \\
IQR & 9.24 & 7.14 \\
\hline
\end{tabular}

Average mining exposure duration of the subjects in miners group was 22.58 years (range 13 to 31 years, SD 5.02). Statistical analysis indicated no significant correlation between exposure duration and FA ANS - calendar age difference (rho $=0.123, \mathrm{p}=0.57$ ). In subjects with shortest exposure low variance of difference can be seen, however, the variance of results rises with rising exposure duration as shown in Fig. 2. 


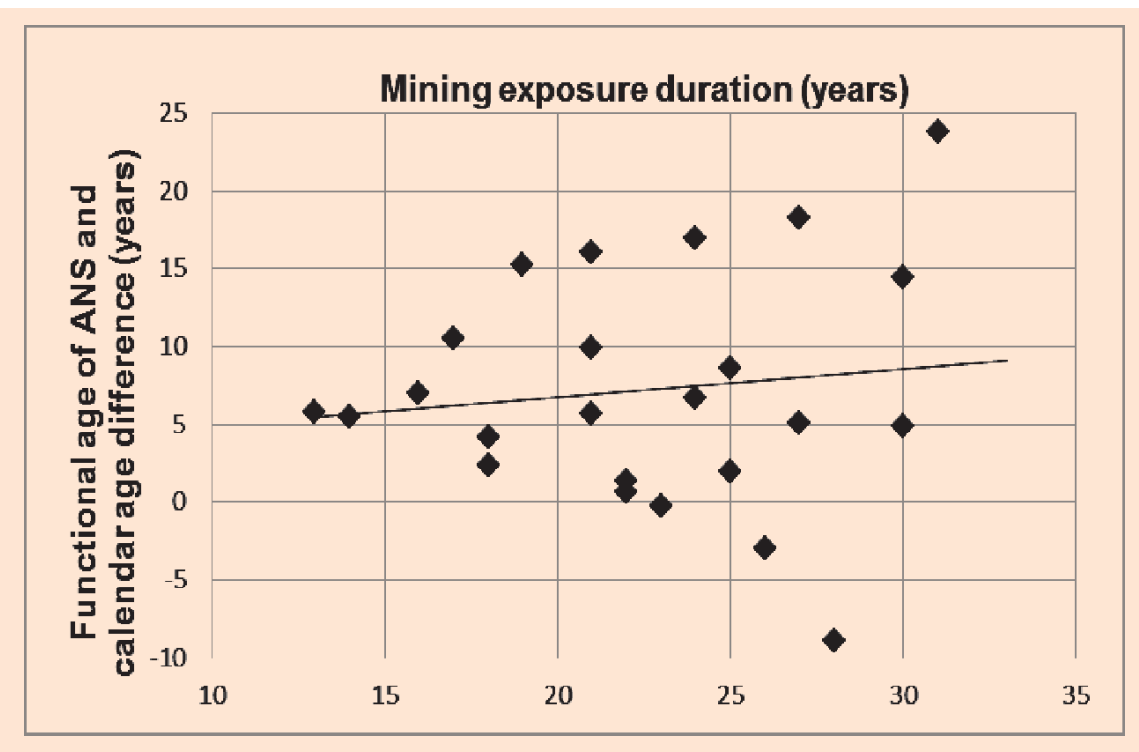

Fig. 2 Relationship between the FA ANS - calendar age difference and the occupational mining exposure duration. No significant correlation was found $(\mathrm{p}=0.57)$

As emerged from the analysis of selected parameters SA HRV and the rMSSD parameter of time-domain analysis, we found lower values of all power spectral parameters and rMSSD and higher $\mathrm{LF} / \mathrm{HF}$ ratio in miners group compared to control group in both subgroups (under and above 48 years of age) and both T2 and T3 phases. Statistically significant differences in the subgroup of the subjects aged under 48 was found only in LF/HF ratio in T3 phase. All parameters except LF/HF ratio appeared significantly decreased in subgroup of the subjects aged 48 and above in miners group (see Table 2 and 3).

Table 2. Mean values of heart rate variability selected parameters from T2 phase (orthostatic position) in subjetcts under and over 48 years old compared between miners and control group (M1 and $\mathrm{C} 1$ - subjects in miners and control group under 48 years old, M2 and C2 subjects in miners and control group over 48 years old). P-values calculated using Mann-Whitney U test. Significant difference between parameters marked by * $(p<0.05)$.

\begin{tabular}{|l|c|c|c|c|c|c|}
\hline $\begin{array}{l}\text { T2 phase } \\
\text { (orthostatic) }\end{array}$ & $\begin{array}{c}\text { M1 group } \\
(\mathrm{n}=11)\end{array}$ & $\begin{array}{c}\text { C1 group } \\
(\mathrm{n}=8)\end{array}$ & $\mathrm{p}$ & $\begin{array}{c}\text { M2 group } \\
(\mathrm{n}=13)\end{array}$ & $\begin{array}{c}\text { C2 group } \\
\text { (n = 9) }\end{array}$ & $\mathrm{p}$ \\
\hline TotPwr $\left(\mathrm{ms}^{2}\right)$ & 794.18 & 1622.10 & 0.968 & 443.28 & 1159.97 & $0.038^{*}$ \\
\hline LF $\left(\mathrm{ms}^{2}\right)$ & 417.06 & 889.57 & 0.772 & 259.94 & 641.90 & $0.046^{*}$ \\
\hline HF $\left(\mathrm{ms}^{2}\right)$ & 128.98 & 383.50 & 0.711 & 42.33 & 198.04 & $0.004^{*}$ \\
\hline LF/HF ratio & 6.08 & 4.85 & 0.772 & 8.39 & 5.40 & 0.124 \\
\hline rMSSD (ms) & 16.46 & 26.24 & 0.772 & 11.09 & 22.11 & $0.006^{*}$ \\
\hline
\end{tabular}


Table 3. Mean values of heart rate variability selected parameters from T3 phase $\left(2^{\text {nd }}\right.$ supination position) in subjetcts under and over 48 years old compared between miners and control group (M1 and $\mathrm{C} 1$ - subjects in miners and control group under 48 years old, M2 and C2 subjects in miners and control group over 48 years old). P-values calculated using Mann-Whitney U test. Significant difference between parameters marked by* $(\mathrm{p}<0.05)$.

\begin{tabular}{|l|c|c|c|c|c|c|}
\hline $\begin{array}{l}\text { T3 phase } \\
\left(2^{\text {nd }} \text { supination) }\right.\end{array}$ & $\begin{array}{c}\text { M1 group } \\
(\mathrm{n}=11)\end{array}$ & $\begin{array}{c}\text { C1 group } \\
(\mathrm{n}=8)\end{array}$ & $\mathrm{p}$ & $\begin{array}{c}\text { M2 group } \\
(\mathrm{n}=13)\end{array}$ & $\begin{array}{c}\text { C2 group } \\
(\mathrm{n}=9)\end{array}$ & $\mathrm{p}$ \\
\hline TotPwr $\left(\mathrm{ms}^{2}\right)$ & 1399.03 & 1919.61 & 0.484 & 740.01 & 2036.40 & $0.006^{*}$ \\
\hline LF $\left(\mathrm{ms}^{2}\right)$ & 398.83 & 380.16 & 0.711 & 264.55 & 764.81 & $0.009^{*}$ \\
\hline HF $\left(\mathrm{ms}^{2}\right)$ & 439.52 & 1154.72 & 0.201 & 283.39 & 701.29 & $0.003^{*}$ \\
\hline LF/HF & 0.90 & 0.47 & $0.019^{*}$ & 2.51 & 1.47 & 0.162 \\
\hline rMSSD (ms) & 36.43 & 60.93 & 0.201 & 22.19 & 44.05 & $0.008^{*}$ \\
\hline
\end{tabular}

\section{DISCUSSION}

The heart rate and HRV are both notably sensitive parameters, which can be susceptible to a large amount of endogenous as well as exogenous factors and respond to a numerous stimuli.

The results of our study show significant increase of the FA ANS in comparison with calendar age in the subjects group with positive mining exposition against the group of nonexposed subjects. Functional age of ANS offers complex ANS activity rating. Increase of FA ANS in subjects with exposition to negative factors of mining work environment notice the changes of autonomic regulation, which are typical for healthy individuals with higher calendar age. Increased FA ANS in 21 of 24 examined subjects in exposed group in comparison with only 6 of 17 subjects in control group at first sight may indicate the considerable influence of negative factors in mining industry on HRV parameters, and therefore, on the cardiovascular autonomic regulation. In this study no correlation between the exposure duration and the absolute change of FA ANS was confirmed, which may also indicate the participation of individual sensitivity of the autonomic nervous system regulatory mechanisms to these occupational negative factors. Other factors can also play a certain role, especially endogenous or non-occupational exogenous factors, which identify and assess the influence on ANS regulation could be not uncomplicated, if possible at all. Results of HRV analysis indicate significant decrease in Total spectral power, LF and HF spectral power and rMSSD parameters in miners above 48 years of age in both orthostatic as well as supination position compared to subjects from control group at the same age, also the $\mathrm{LF} / \mathrm{HF}$ ratio increased, but no significance was confirmed. In subjects under 48 years of age only significant increase of LF/HF ratio was found in miners group in orthostatic position, only non-significant changes were observed in other parameters in both orthostatic and supination positions. This results indicate impaired autonomic regulation particularly in elderly subjects with occupational mining exposure compared to unexposed subjects manifesting itself by reduced the total HRV and the parasympathetic activity, and probably the sympathetic activity to a certain extent.

The recent studies demonstrate significant decrease in SA HRV parameters HF, LF and HF/LF ratio after workload exposure (9), these changes were more significant in older workers. Studies also indicate increased risk of cardiovascular morbidity and mortality after long-time occupational workload (10). On the other side, the free-time physical activity con- 
tributes to the total HRV increasing and the cardiovascular risks decreasing (11). The noise, except causing the hearing loss, plays role as an important stressor with characteristic cardiovascular response (tachycardia, hypertension). Short-term noise exposure leads to increase of the sympathetic activity (12), so does the long-term noise exposure, probably by increased sympathetic activity or mild cardiovascular dysregulation, that leads to increased risk of myocardial infarction development (13), to three-times increased risk of stroke and $60 \%$ increased risk of sudden cardiovascular death (14). Sympathetic hyperactivity has been observed in connection with noise exposure $(15,16)$. Shift work is characterized by disturbing the circadian rhythm of ANS due to requirement of increased sympathetic activity during expecting rest-time (12), reducing the total $\operatorname{HRV}(17,18)$ and significant increasing the LF/HF ratio (18). Effect of vibrations was described by reduced sympathetic and as well as parasympathetic activity and by shifted ANS activity to the sympathetic dominance (19, 20). The results of another studies show association of reduced HRV, especially during daytime, with increased risk of cardiovascular diseases, predominantly coronary artery disease, stroke and other (21). Reduced vagal activity presents an independent risk factor for mortality of any causes and general factor of all cardiovascular risk factors (22). Work-related stress by itself comprises one of the cardiovascular morbidity major risk factors (22). The autonomic imbalance characterized by sympathetic hyperactivity with vagal hypoactivity is connected with the pathological conditions convenient for atherosclerotic changes development (22). A combination of the sympathetic hyperactivity and hypertension represents an increased risk of cardiovascular diseases development (23).

According to the mentioned studies, deterioration of HRV parameters, anyway increase the FA ANS compared to calendar age, can represent such changes in the cardiovascular autonomic regulation, which are present in healthy individuals of the more advanced age. Those conditions in subjects with increased FA ANS can lead to development of more severe cardiovascular diseases at a younger age, earlier progression the pre-existing cardiovascular diseases or possibly earlier development of serious complications of these diseases.

\section{Limits of the study}

Some external influences (e.g. incipient diseases especially in older subjects, alimentation, non-professional exposure etc.) could be unrecognized or underestimated, even though we tried to exclude them using the entrance questionnaire. Due to nonparametric distribution of results in subgroups, non-parametric tests in SA HRV evaluation were applied. The time and frequency domain HRV analysis methods applied in this work prove lower sensitivity to autonomic dysfunction than non-linear methods do.

\section{CONCLUSION}

There are many risk factors from mining work environment having influence on formation and progression of various cardiovascular diseases. Our results indicate that influence of these occupational risk factors can participate in deterioration of ANS reactivity to a certain extent, of course, taking individual sensitivity and impact of non-occupational factors deteriorating ANS reactivity into consideration.

The methodology of evaluating the complex indices and other SA HRV parameters after long-term exposure to the negative occupational factors not only in mining work environment, predominantly in the elderly workers, applied to the clinical practice could be used to detect the changes in autonomic cardiovascular regulation, which could lead to earlier development or progression of cardiovascular diseases with continuing exposure to negative occupational factors or interacting with other non-occupational risk factors. 


\section{REFERENCES}

1. Statistical Office of the Slovak Republic. Yearbook of Industry 2015. Bratislava, 2015.

2. Malik M. Heart rate variability: Standards of measurement, physiological interpretation, and clinical use. Task Force of the European Society of Cardiology and the North American Society of Pacing and Electrophysiology. Eur Heart J. 1996; 17(3): 354-81.

3. Voss A, Schroeder R, Heitmann A, Peters A, Perz S. Short-Term Heart Rate Variability-Influence of Gender and Age in Healthy Subjects. Hernandez AV, ed. PLoS ONE. 2015;10(3).

4. Salinger J, Gwozdziewicz M. Systémy použivané pro vyšetření krátkodobé variability srdeční frekvence. In: Javorka $\mathrm{K}$ et al. Variabilita frekvencie srdca: Mechanizmy, hodnotenie, klinické využitie. Martin: Osveta, 2008. p. 57-64.

5. Stejskal P, Šlachta R, Elfmark M, Salinger J, Gaul-Áčová P. Spectral analysis of heart rate variability: New evaluation method. Acta Univ. Palacki. Olomouc. Gymn. 2002; 32(2): 13-18.

6. Javorka K, Javorka M. Variabilita frekvencie srdca - mechanizmy a význam. In: Javorka K et al. Variabilita frekvencie srdca: Mechanizmy, hodnotenie, klinické využitie. Martin: Osveta, 2008. p. 28-37.

7. Goldstein DS, Bentho O, Park MY, Sharabi Y. Low-frequency power of heart rate variability is not a measure of cardiac sympathetic tone but may be a measure of modulation of cardiac autonomic outflows by baroreflexes. Exp Physiol. 2011; 96(12): 1255-61.

8. Otzenberger H, Gronifer C, Simon C, Charloux A, Erhart J, Piquard F, Brandenberger G. Dynamic heart rate variability: a tool for exploring sympathovagal balance continuously during sleep in men. Am J Physiol. 1998; 275(3 Pt 2): H946-50.

9. Kang D, Kim Y, Kim J, Hwang Y, Cho B, Hong T, Sung B, Lee Y. Effects of high occupational physical activity, aging, and exercise on heart rate variability among male workers. Ann Occup Environ Med. 2015; 27: 22.

10. Hu GC, Chien KL, Hsieh SF, Chen CY, Tsai WH, Su TC. Occupational versus leisure-time physical activity in reducting cardiovascular risks and mortality among ethnic Chinese adults in Taiwan. Asia Pac J Public Health. 2014; 26(6): 604-13.

11. Hautala AJ, Kiviniemi AM, Tulppo MP. Individual responses to aerobic exercise: The role of the autonomic nervous system. Neurosci Biobehav Rev. 2009; 33(2): 107-15.

12. Van Amselvoort LG, Schouten EG, Maan AC, Swenne CA, Kok FJ. Occupational determinants of heart rate variability. Int Arch Occup Environ Health. 2000; 73(4): 255-62.

13. Ising H, Babisch W, Kruppa B, Lindthammer A, Wiens D. Subjective work noise: a major risk factor in myocardial infarction. Soz Praventmed. 1997; 42(4): 216-22.

14. Gopinath B, Thiagalingam A, Teber E, Mitchell P. Exposure to workplace noise and the risk of cardiovascular disease events and mortality among older adults. Prev Med. 2011; 53(6): 390-4.

15. Goyal S, Gupta V, Walia L. Effect of noise stress on autonomic function tests. Noise Health. 2010; 12(48): 182-6.

16. Tassi P, Saremi M, Schimowitsch S, Eschenlauer A, Rohmer O, Muzet A. Eur J Appl Physiol. 2010; 108(4): 671-80.

17. Bonnet $\mathrm{MH}$, Arand DL. Heart rate variability in insomniacs and matched normal sleepers. Psychosom Med. 1998; 60(5): 610-5.

18. Wehrens SM, Hampton SM, Skene DJ. Heart rate variability and endothelial function after sleep deprivation and recovery sleep among male shift and non-shift workers. Scand J Environ Health. 2012; 38(2): 171-81.

19. Laskar MS, Harada N. Assessment of autonomic nervous activity in hand-arm vibration syndrome patients using time- and frequency-domain analyses of heart rate variation. Int Arch Occup Environ Health. 1999; 72(7): 462-8.

20. Sakakibara H, Luo J, Zhu SK, Hirata M, Abe M. Autonomic nervous activity during hand immersion in cold water in patients with vibration-induced white finger. Ind Health. 2002; 40(3): 254-9.

21. Schuster AK, Fischer JE, Thayer JF, Mauss D, Jarczok MN. Decreased heart rate variability correlates to increased cardiovascular risk. Int J Cardiol. 2016; 203: 728-30.

22. Thayer JF, Yamamoto SS, Brosschot JF. The relationship of autonomic imbalance, heart rate variability and cardiovascular disease risk factors. Int J Cardiol. 2010; 141(2): 122-31.

23. Grassi G, Seravalle G, Quarti-Trevano F, Dell'Oro R, Arenare F, Spaziani D, Mancia G. Sympathetic and baroreflex cardiovascular control in hypertension-related left ventricular dysfunction. Hypertension. 2009; 53(2): 205-9.

Received: April, 13, 2016

Accepted: April, 20, 2016 